Portland State University

PDXScholar

$1-2014$

\title{
High Latitude Coastal Settlement Patterns: Cape Krusenstern, Alaska
}

Shelby L. Anderson

Portland State University, ashelby@pdx.edu

Adam Freeburg

University of Washington

Follow this and additional works at: https://pdxscholar.library.pdx.edu/anth_fac

Part of the Archaeological Anthropology Commons, and the Social and Cultural Anthropology Commons

Let us know how access to this document benefits you.

\section{Citation Details}

Anderson, Shelby L. and Freeburg, Adam, "High Latitude Coastal Settlement Patterns: Cape Krusenstern, Alaska" (2014). Anthropology Faculty Publications and Presentations. 32.

https://pdxscholar.library.pdx.edu/anth_fac/32

This Post-Print is brought to you for free and open access. It has been accepted for inclusion in Anthropology Faculty Publications and Presentations by an authorized administrator of PDXScholar. Please contact us if we can make this document more accessible: pdxscholar@pdx.edu. 


\title{
HIGH LATITUDE COASTAL SETTLEMENT PATTERNS: CAPE KRUSENSTERN, ALASKA
}

Shelby L. Anderson, Portland State University

Adam K. Freeburg, University of Washington, National Park Service

\begin{abstract}
:
Why, when, and how people developed highly specialized marine economies remains the focus of considerable anthropological research. Study of maritime adaptations at high latitudes has potential to contribute to this debate because low biodiversity and increased resource seasonality at high latitudes made reliance on marine resources particularly risky. New research at the Cape Krusenstern site complex, located in northwest Alaska, offers a rare opportunity to study the evolution of maritime adaptations across the environmentally dynamic mid-to-late Holocene Arctic. Large-scale and systematic survey of this important site complex was undertaken to address questions about the timing and character of early Arctic coastal lifeways. Our research yielded direct dates of 4200 years ago for the oldest occupation of the site complex and identified several new sites dating to between 4200 and 2000 years ago. Results support the existing settlement model, pointing to increased sedentism and local population only after 2000 years ago. New data, however, indicate local population was much higher than previously established and that coastal occupation was sustained over long periods of time despite considerable mid-to-late Holocene paleoenvironmental variability. Together, these findings raise new questions about the evolution of maritime adaptations at high latitudes.
\end{abstract}

Keywords: settlement patterns, hunter-gatherers, maritime adaptations, Arctic 


\section{Introduction}

Archaeologists have long been interested in why, how, and when foraging peoples turn to marine resources as their primary mode of subsistence. Until recently this was widely considered a relatively late development on a worldwide level but the evidence for early marine and aquatic subsistence is growing(see discussion in Erlandson 2001; Erlandson and Rick 2010). Marine resource use is linked in many cases to the development of larger populations, increased sedentism, increased technological complexity, and in some cases, the emergence of social complexity (e.g. Ames 1994; Erlandson 2001; Fitzhugh 2003; Yesner 1998). Maritime routes navigable only by people already adapted to a marine focused lifeway may have been key for populating North and South America (Erlandson and Braje 2011; Erlandson, et al. 2007; Erlandson, et al. 2008; Erlandson, et al. 2011). Many questions remain about why, in some cases, people chose to invest in specialized marine technologies and engage in high risk/high reward marine hunting. Study of maritime adaptations at high latitudes is particularly informative because of low biodiversity and increased seasonality in resource availability in these environments (Rowley-Conwy 1999) that would have made subsistence focus on relatively few species, in this case marine-based, especially challenging. Environmental change or increased environmental variability may have further increased this already high risk of marine resource use. New research at the Cape Krusenstern site complex, located in northwest Alaska (Figure 1), offers a rare opportunity to study the development of maritime adaptations across the environmentally dynamic mid-to-late Holocene Arctic.

The Cape Krusenstern site complex is one of the most well-known coastal archaeological sites in northern North America. As part of the greater Bering Strait region, the archaeology of the Cape Krusenstern site complex is representative of the complex history of movement and interaction across the Strait over many millennia. Over the last $4000-4500$ years, coastal forager populations occupied the approximately 3000 hectare site complex. All of the major archaeological cultures identified in the 
western Arctic are known at Cape Krusenstern including Denbigh (or Arctic Small Tool Tradition), Choris, Norton-Near Ipiutak, Ipiutak, Birnirk, Thule, Kotzebue, and Historic Iñupiat. The Denbigh (4500-2750 B.P.)sites at Cape Krusenstern are among the earliest preserved evidence of coastal foraging in northern Alaska; any older coastal sites are now underwater as a result of early Holocene sea level rise (Erlandson, et al. 2007; Jordan and Mason 1999; Mason and Jordan 1993, 2002; Mason, et al. 1995). Subsequent occupations at the site complex represent the development of a highly specialized maritime lifeway during the late Holocene, which may have enabled the migration and sustained colonization of people eastward across the North American Arctic and High Arctic. Uncertainty remains about the timing and character of the development of maritime adaptations in the Western Arctic and Subarctic. In northwest Alaska, the earliest evidence of increasing marine resource focus dates to about 2500 3100 years ago. Evidence includes increased coastal sedentism, faunal data, and tool technologies (Giddings and Anderson 1986). Prior to this, seasonal use of coastal resources is primarily indicated during the Denbigh period by the presence of short term occupations on the coast and marine hunting or fishing tools at some of these sites (Ackerman 1998; Anderson 1984). The evidence for maritime adaptations is much earlier in southern Alaska, dated to about 9000 years ago in the Aleutians (Aigner 1976; Laughlin and Aigner 1966) and 7500 to 7000 years ago on the Kodiak Archipelago (Fitzhugh 2003). Current explanations for this pattern include differences in marine ecology north and south of the Bering Strait (Anderson 1984), taphonomic effects of sea level rise and other coastal processes (Erlandson and Braje 2011), and regional differences in marine productivity linked to paleoclimatic change (Fitzhugh in review). This paper focuses on the timing, character, and evolution of coastal occupation at high latitudes through a study of changing settlement patterns at Cape Krusenstern. The results of this work offer new insights into the evolution of a settled or committed maritime lifeway, which have implications for current research on maritime adaptations.

\section{The Cape Krusenstern Site Complex}


The Cape Krusenstern site complex is one of several beach ridge systems that ring the Chukchi Sea. Around the region, beach ridge systems began forming soon after regional sea level stabilized between 4000 and 6000 years ago (Jordan and Mason 1999; Mason and Jordan 1993, 2002). These ridges developed and prograded over centuries during periods of low storm frequency. During periods of higher storm frequency, some beach ridges eroded or were re-worked. Over time, extensive beach ridge systems like Cape Krusenstern developed and now serve as a record of local and regional coastal environmental change. People visited the Cape Krusenstern beach ridges soon after they began to form, with early sites at the Cape indirectly dated by Giddings to between 4000 and 4500 years ago (Giddings and Anderson 1986). Over time, the beach ridges prograded and people moved the majority of their activities to the ridges nearest the ocean. As a result, the beach ridges form a 'horizontal stratigraphy' (Giddings 1966) that serves as a record of both past coastal environmental conditions and human settlement of the site complex. The oldest beach ridges and archaeological sites are located near the modern day lagoon, with progressively younger ridges and archaeological sites located toward the present day sea shore. Prior to widespread use of radiocarbon dating in archaeology, the horizontal stratigraphy at Cape Krusenstern was key to the establishment of the northern Alaskan archaeological chronology. Giddings organized archaeological finds from Cape Krusenstern and other sites around the coasts and interior of Kotzebue Sound (e.g. Giddings 1938, 1940, 1941, 1942, 1948, 1951, 1952a, 1961) into a chronological framework by correlating the horizontal stratigraphy at Cape Krusenstern with the deeply stratified Onion Portage site (Anderson 1988; Giddings 1966; see Meitl 2008 for new dates)(Figure 1).

Various researchers (e.g. Giddings 1966; Giddings and Anderson 1986; Hopkins 1977; Moore $1960,1966)$ recognized the potential of Arctic beach ridge systems for studying coastal environmental and cultural change. Giddings grouped Cape Krusenstern beach ridges into what he called beach ridge "segments" based on geomorphological and archaeological evidence (Figure 2)(Table 1). The most 
pronounced beach ridge discontinuities, created by periods of erosion, represent significant changes in the coastal environment that coincide with key cultural transitions (Mason and Jordan 1993).

Subsequent researchers refined this beach segment system and linked it to other beach ridge systems around Kotzebue Sound to reconstruct a regional coastal storminess record (Mason and Jordan 1993; Mason, et al. 1995; Mason and Ludwig 1990). Mason and Jordan (1993) studied the morphology of the ridges at Cape Krusenstern and other Chukchi Sea beach ridge systems to reconstruct late Holocene weather patterns, changing coastal depositional regimes, and regional sea level change.

\section{Western Arctic Coastal Settlement Patterns}

The general model of maritime adaptations in the western Arctic was developed primarily through research by Giddings at Cape Krusenstern and around Kotzebue Sound (e.g. Giddings 1942, 1948, 1951, 1952a, 1952b, 1957, 1961, 1964, 1966, 1967; Giddings and Anderson 1986). This research primarily used settlement pattern and technological data to demonstrate increased focus on marine resources over time, although some limited faunal analyses were also carried out. Subsequent research in the surrounding region did not significantly revise this coastal settlement model (e.g. Anderson 1972, 1977; Anderson and Anderson 1977; Harritt 1994; McClenahan and Gibson 1990; Schaaf 1988). Giddings and Anderson (1986:320) describe the earliest occupations at the site complex, dated to between 4200 and 3600 years ago as small spring or summer seal hunting campsites left behind by highly mobile foragers with a generalized subsistence economy. These Denbigh occupations do not contain any preserved faunal material but some tool types suggest marine hunting activities (Giddings and Anderson 1986; see also Ackerman 1998). This pattern persisted at the Cape from 3600 to about 2000 years ago, although semi-permanent coastal sites from this time are known in other parts of northwest Alaska at coastal sites on the Choris Peninsula (Giddings 1957), on the northern Seward Peninsula coast northeast of Wales and at the Onion Portage (Anderson 1988:111) site (Figure 1). An exception to this settlement pattern is the Old Whaling site, which includes several semi-permanent house structures, both summer 
and nearby winter occupations, that are dated to between about 3100 and 2500 years ago (Giddings and Anderson 1986:32; Darwent and Darwent 2005, Darwent 2006). The age, origins, and character of the Old Whaling site are the subject of much debate. Giddings (Giddings and Anderson 1986) initially interpreted the site as a unique settlement of an early whaling people based on the tool kits and whale bone recovered from the site. The oldest preserved faunal materials at Cape Krusenstern are from the Old Whaling site (Giddings and Anderson 1986). Old Whaling has since been compared to several Siberian sites including the Devil's Gorge site on Wrangel Island (Ackerman 1998) and the Un'en'en site on the Chukotka Peninsula coast (Pringle 2008; Witze 2008). Evidence for whaling at the site is disputed, with recent reanalysis of faunal materials indicating an emphasis on small seals rather than whales (Darwent 2006; Darwent and Darwent 2005). Large harpoon endblades recovered from the site (Giddings and Anderson 1986), however, suggest some hunting of walrus and large seals if not whales.

The presence of semi-subterranean occupation features at Cape Krusenstern after 2000 years ago were interpreted by Giddings and Anderson as evidence of winter or cold season occupation of coast areas. These structures are time-consuming and costly in terms of raw materials to build. While people likely lived for extended periods of time on the coast before these structures were built, the switch to these more substantial and higher investment structures are considered a sign of an increased commitment to and/or reliance on marine resources and life on the coast. An increase in the number of features and sites during this same period indicate local population increase. Faunal data from Cape Krusenstern and Point Hope show that during this period people were primarily consuming marine resources, mainly ringed seals (Giddings and Anderson 1986; Larsen and Rainey 1948). The pattern of increasingly large and longer term occupation of coastal sites persists around the region and at Cape Krusenstern for the next 1500 years. Increased population was accompanied by various changes in technology and subsistence. It was during this period that there is clear evidence of whaling around the 
Bering Strait region along with an overall increase in marine resource specialization based on both faunal and technological data (e.g. Mason 1998, 2009a, 2009b; Mason and Bowers 2009).

Between about 1200 and 500 years ago, faunal data from Cape Krusenstern show a significant drop in marine mammal use and a corresponding rise in the importance of caribou (Giddings and Anderson 1986). Thule subsistence and settlement did not follow this pattern everywhere. Whaling continued on coastal promontories near whale migratory routes such as Barrow, Wales, and Point Hope and in the Bering Strait (Mason 1998). After 500 cal BP, Giddings and Anderson (1986) identified a decrease in the number of sites at Cape Krusenstern and other locations around northwestern Alaska. Drawing on evidence from around the region, Giddings and Anderson concluded that although people continued to live a semi-sedentary lifestyle, post-500 cal BP settlements were located in previously unoccupied areas of the coasts and river systems of the region and that people shifted their focus from marine mammals to fishing (Giddings and Anderson 1986: 33, 107).

\section{Legacy Data Analysis}

To address some of the issues with the existing chronology and prior work at Cape Krusenstern (e.g. Mason and Ludwig 1990:363-365) we relocated previously recorded sites and reanalyzed previously reported, or legacy, data as part of our research effort. Integrating problematic existing data sets into the current investigation was critical in light of the importance of prior work at the site on our understanding of high latitude maritime adaptations. In the early stages of this project we carried out archival research at the National Park Service (NPS) curation facility in Anchorage and at Brown University's Haffenreffer Museum, a repository for many of Giddings' collections, with the purpose of collecting unpublished data on prior Cape Krusenstern research. Sources of legacy data included published data (Giddings 1966, 1967; Giddings and Anderson 1986), two USGS airphoto mosaics annotated in ink by Giddings (Douglas D. Anderson, personal communication 2008), a feature catalog at 
the Haffenreffer and data from the NPS. During a visit to the Haffenreffer Museum in February 2008, two original annotated photomosaics were located; one with beach ridge numbers and one with numbered feature locations. Digital photos were taken of overlapping portions of the original photomosaics. These images were imported into GIS software where they were rubbersheeted and georeferenced (Conolly and Lake 2006). This involved the use of stable lagoon and lakeshore features within the beach ridge complex as reference points to match the 1950 s airphoto data to recent orthographic imagery (Manley et al. 2007). The airphotos were then stretched to a known projection and connected to geographic locations in GIS. The handwritten annotations were then digitized as points in the GIS. The spatial placement of each annotated point was checked against ground features visible on the recent orthoimagery.

In some locations it was possible to confirm legacy site locations in GIS using published maps and new orthographic imagery. This was most successful in the case of large, previously excavated features such as houses that were never backfilled and thus are fairly obvious in orthographic imagery. In these cases, legacy data points were moved from their original locations as marked on Giddings' air photos to their actual location in geographic space. The result of this work was a spatially referenced database of previously recorded sites and features that we could use to make survey design decisions and to relocate key settlements during fieldwork. We added tabulated feature data from Giddings and Anderson (1986), the NPS archives, and Giddings' feature card catalog to the legacy database. Feature types were coded based on written descriptions for analysis. We also digitized Giddings' beach ridge segments from published maps (Giddings and Anderson 1986) and used these as analytical units (see Figure 2). Our use of the annotated airphoto and orthoimagery is similar in some ways to Zimmerman's (1981) effort to predict site locations at Cape Krusenstern. Problems encountered in the process of creating the legacy database include issues with missing and duplicate feature numbers, unfamiliarity with the original numbering system, and numerous features noted in the publication or unpublished 
documentation that are not marked on the original air photo. Many of these issues were resolved through cross-checking feature information across the sources of legacy data available to us and through field relocation of legacy sites.

The legacy feature database is comprised of 639 legacy features (Table 2). We were able to link 599 of these features to a beach segment, with geographic coordinates available for the 480 features that were annotated on Giddings' aerial photograph. 361 of these features were located within the current survey areas (Table 3). 639 legacy features should be considered a conservative estimate of what prior researchers identified at the site complex. It is highly probable that prior researchers identified more sites than this estimate reflects but did not note them on the aerial photographs or in any field documentation. An additional 14 features mentioned in various published and unpublished sources did not have unique numerical designations and were therefore not included in subsequent analysis.

\section{Survey and Radiocarbon Dating Methods}

Field methods included survey and sample collection as well as precise mapping of archaeological and environmental features across the beach ridges. Although a $100 \%$ survey of the site complex was desirable from both a research and a resource management perspective, the size of the beach ridge complex necessitated sampling. Several priorities and sources of information were used to select survey areas within the beach ridge complex. These included: 1) sampling across both time and space were needed to address project objectives; 2) relocating and testing previously identified sites; 3 ) sampling across major disconformities identified by prior research; 4) avoidance of low-lying areas visible on orthoimagery that were likely to have a high water table that would make sub-surface testing difficult. Within survey areas, survey transects were conducted on beach ridges and not the low-lying swales between them for the same reason. 
Survey of each beach ridge from swale to swale involved a team of archaeologists surveying with $10 \mathrm{~m}$ transect spacing and excavating $30 \mathrm{~cm}$ diameter shovel tests every 40 meters. Coring or auguring was not an option because of the unconsolidated pebble size substrate of the majority of the beach ridge complex. Subsurface tests were also conducted in and/or around suspected cultural features as identified by surface expressions of vegetation, local topography, or other indications. Samples for radiocarbon dating and other analyses were collected from shovel tests. In areas of the beach ridge complex where surface visibility was better than $80 \%$, subsurface testing was not conducted. Some areas were surveyed non-systematically for various reasons, including time constraints, landowner permission, and low archaeological probability. Non-systematic methods included surface-only survey at 10 meter transect intervals as well as limited subsurface testing focused on potential cultural features. All archaeological features and artifacts were recorded with mappinggrade GPS, as were areas of anomalous vegetation. Use of high accuracy GPS units with post-processing capability to collect spatial data was central to gathering the quality of data needed to address research questions. GPS technology allowed rapid recording of feature size, shape, and condition information as field crews surveyed the beach ridge complex. Trimble GeoXH and ProXH units with Zephyr antennas used to collect data can be accurate to within $20 \mathrm{~cm}$ after post-processing.

Samples for radiocarbon dating were collected from shovel tests and from larger square test units, usually 1 by 1 meter in size. Material from test units was screened using $1 / 4^{\prime \prime}$ and $1 / 8^{\prime \prime}$ screen, while material from shovel tests was troweled through but not screened. A total of 57 test units were excavated. The majority of these were in surface evident features that were not clearly occupation structures. These test units were judgmentally placed based on the results of shovel testing. In selecting samples to date, we focused on sampling across the beach ridge complex and from locations near previously identified disconformities in the beach ridge landscape. In addition, our goal was to sample a diversity of feature types in order to better understand changing settlement patterns over time. We 
obtained multiple samples from apparent settlements, or clusters of archaeological features, to learn more about the contemporaneity of features in these sites. Although the ideal would have been to date terrestrial mammal bone, we recovered very few terrestrial mammal specimens. Instead, we dated shorter-lived species (e.g. willow or birch) where possible to address the problem of old wood in this setting.

We obtained 151 new dates (see Anderson and Freeburg in press). Two dates obtained on marine mammal bone, three anomalously old dates, and a date that yielded a modern age were excluded from this analysis. In addition, 10 dates from uncertain feature types or contexts were excluded from this analysis (See Anderson and Freeburg in press for dates). Lastly, in a few cases where multiple dates were obtained from the same feature, only the date from the deepest context was included in this analysis to avoid inflating local population estimates based on radiocarbon dates. The remaining 125 conventional radiocarbon dates were calibrated and plotted using Oxcal version 4.1 (Bronk Ramsey 2009) and Intcal 09 (Reimer, et al. 2009)(Table 4). Use of radiocarbon dates as a proxy for population is problematic (Ames 2000; Erlandson and Moss 1999; Louderback, et al. 2011; Surovell and Brantingham 2007; Surovell, et al. 2009; Williams 2012) and best used in combination with other population estimate methods, such as number of sites (e.g. Fitzhugh 2003). Here we consider summed plots of dated features as a very rough proxy for local population in combination with feature counts. Features are used instead of sites as a second proxy for local population because of density of archaeological occupations at the site complex makes site boundary delineation difficult. Furthermore, dated feature information is comparable to prior regional efforts to estimate population change (e.g. Mason 1998).

\section{Results and Discussion}

Approximately 1205 hectares of the 3300 hectare beach ridge complex, about $36 \%$ of the site complex, were surveyed in four seasons of fieldwork conducted between 2006 and 2010 (Figure 
3)(Table 5). An additional 340 hectares were either surveyed systematically but with limited subsurface testing or surveyed non-systematically. A total of 1377 archaeological features (e.g., houses, campsites, surface scatters, etc.) were identified and mapped (Table 6).

The horizontal stratigraphy at the site complex has long been considered a rough but reliable chronological framework for the western Arctic. New radiocarbon dates obtained as part of this project, however, indicate that occupation of beach segments was overlapping rather than sequential. This overlap is significant in some cases. For example, occupation of beach segments I and II overlap for nearly 1000 years. In other words, new dates show that the horizontal stratigraphy is mixed. These findings led us to revise the upper limiting ages for the beach segments (Table 1) and to interpret feature frequency data with some caution. The significance of these chronological issues are explored in more depth elsewhere (Anderson and Freeburg in press; Freeburg and Anderson 2012). We focus here on the results of dating in relationship to settlement pattern interpretation. We use Giddings' beach ridge segment delineations to evaluate the efficacy of our survey and to facilitate comparisons between our data and prior research before turning to the results of radiocarbon dating to further interpret these data.

Because of differences in survey coverage within each beach segment, results are quantified with respect to the relative area surveyed within each beach segment (Figure 4). Specifically, the number of features identified by the current project and by prior research were divided by the number of square km surveyed by the current project. Comparison of newly collected data to legacy data (Figure 4) indicates that the most recent survey identified more features than previously documented. This is due in part to the issues with tallying legacy features noted above and also the increased survey intensity of the current project. In particular, our survey identified many more features in segment III and IV in the central areas of the beach ridge complex than were identified by prior work. As expected with a larger and more systematic sample size, the current survey identified more "rare" feature types 
such as burials, surface scatters, and hearths. This was particularly the case in the older areas of the beach ridge complex (i.e. segments VI, V, and IV). The relative abundance, however, of each type of feature identified by the current project is about the same at any given time period in the past as established by Giddings and Anderson (1986)(Figures 5 and 6). Despite methodological differences, our results indicate that data collected through prior work were a representative sample of the sites and features at the site complex. An exception to this is the identification of many more indeterminate features by the current project. Indeterminate features are isolated surface depressions, typically greater than 4 square meters in size, which do not have surface visible tunnels or multiple rooms that would clearly indicate that they are occupation structures. Indeterminate features contained artifacts and/or other cultural material and were clearly cultural in origin, which distinguishes these features from vegetation anomalies. Increased identification of indeterminate features by the current project is most likely due to differences in how feature types were defined and attributed, as well as a reduced emphasis on sub-surface testing by the current project.

The frequency of legacy features in the oldest beach segment, $\mathrm{VI}$, is low and is even lower in beach segment V (Figure 4). Legacy feature frequency increases in segment IV, decreases in segment III, and then increases during occupation of beach segments II and I. In contrast, new data indicate an increase in feature frequency during occupation of segment $\mathrm{V}$, a decrease during occupation of segment IV, and an increase in feature frequency during occupation of segments III through I (Figure 4). The results of radiocarbon dating corroborate these general trends over time in feature frequency and provide some additional detail (Figure 7). Occupation frequency is low between 4200 and 2800 years ago. Occupation frequency increases somewhat between 2800 and 2000 years ago, and then increases significantly beginning around 2000 years until 1300 years ago. A decrease in occupation between about 1300 and about 1000 cal BP is apparent, followed by a sharp increase between about 1000 and 900 years ago. Another decrease in dated sites is apparent between 900 and 800 years ago, with a 
subsequent increase in occupation between about 800 and 500 cal BP. The number of dated features decreases rapidly after 500 years ago. The oldest feature types at the site complex are hearths, activity areas, and surface scatters (Figure 8) as identified by Giddings and Anderson (1986). With the exception of the older dates obtained on the Old Whaling houses, semi-permanent house structures are not present until about 2800 years ago and increase in abundance only after 2000 years ago. Indeterminate features also increase in abundance after 2000 years ago. Cache pits are not present until about 1000 years ago and are relatively abundant until about 500 years ago (Figure 8).

Local environmental conditions, past landscape evolution, and survey bias could play a role in shaping the patterns observed in these survey data. Surface vegetation, local ridge topography, depth of burial, and depositional context all factor into the potential for archaeological feature identification and reliability of data based only on surface survey measurements. In general, there is less vegetation and better surface visibility on the older beach ridges (Beach Segments VI). The central part of the site complex (Beach Segment IV and V), is difficult to access and survey because of the wet conditions. Large areas of standing water have to be traversed to reach a few higher and drier beach ridges. While sites could be located in areas of standing water, they are difficult to identify. Lastly, variability in local topography and coastal depositional processes following abandonment of archaeological features mean that some features are likely more deeply buried than others and therefore harder to identify through surface survey and limited sub-surface testing. There is currently no way to account for these potential effects on survey results.

Landscape evolution at the beach ridge complex is also a likely mitigating factor in the number and type of sites identified during particular time periods. Drawing on dates from archaeological sites, prior research established that significant periods of erosion occurred at Cape Krusenstern around 3000 ${ }^{14} \mathrm{C}$ yr BP and again at about $1200-1000{ }^{14} \mathrm{C}$ yr BP $(900-1000 \mathrm{cal}$ AD/1050-950 cal BP)(Mason and Jordan 1993:63). The later erosion episode could explain the drop in site density between 1300 and about 1000 
cal BP to some extent; the absence of sites dating to this period may actually provide a broader range for the latest episode of sustained erosion at Cape Krusenstern. Furthermore, a significant gap in the dated features between 3600 and 3400 years ago may indicate either a previously unidentified period of coastal erosion or an episode of decreased use of this coastal area. The continuing presence of a few houses, cache pits, and indeterminate features dated to this period (Figure 8), however, indicates that the decrease in site density is not due to taphonomic effects alone. Forthcoming paleoenvironmental and landscape reconstruction data (James Jordan, personal communication 2013) will facilitate further consideration of the impact of past landscape evolution on archaeological site preservation. These data may also lead to a more nuanced understanding of why people chose to camp or live in particular areas of the beach ridge complex with respect to local environment and resource distribution. While our survey was systematic it was not random. Preference was given to areas deemed higher potential for past occupation and also for site visibility. This may have biased our results away from features such as activity areas or deeply buried sites in the swales between beach ridges. While acknowledging these possible confounding or mitigating factors, the systematic approach to survey and data collection allows us to both understand potential limitations or biases and also gives strength to our interpretation.

With the exception of the Old Whaling site, no evidence of longer term occupation, e.g. tent frame floor areas, were identified by prior researchers at the site complex before 2000 BP. Based on the identification of several earlier occupation structures that includes semi-subterranean houses on the Choris Peninsula (Giddings 1957; Giddings and Anderson 1986), several pre-2000 BP house structures at Onion Portage (Anderson 1988), and a structure at the Hicks site in the Brooks Range (Odess 2003), we thought it possible for our more intensive and systematic survey to identify additional early longer term occupations at the site complex, perhaps contemporaneous with the Old Whaling site. While we did not identify any clear semi-subterranean structures or structures similar to those at the Hicks site, several activity areas (OS-81610,81749, 81621, 81682, and 81685), and a probable house feature (OS-81753) 
were dated to before 2000 cal BP. With the exception of one activity area (OS-81685), all of the activity areas with older dates are located in segment IV. Sample OS-81685 was obtained from an activity area in beach segment $\mathrm{V}$. The probable house was located in beach segment III. These features merit additional investigation as they could be the remains of seasonal camps or more substantial structures from early sustained occupation of the coast. Several hearth and surface scatters dated to between 3215 and 4238 cal BP support prior investigators' indirect dating of the earliest occupations at the site to around 4200 years ago.

With the exceptions noted above, our findings give additional support to Giddings and Anderson's (1986) interpretation of seasonal use of the site complex prior to 2000 years ago. They also show that local population was much higher throughout the last 4200 years than previously established. After about 2000 years ago, there are significantly more sites and more semi-permanent settlements at Cape Krusenstern with increased sedentism indicated by the presence of semi-subterranean houses and associated storage features (i.e. cache pits). The increase in storage features associated with post-2000 BP house structures further suggests an expanding population and a change in subsistence and settlement organization, with an increased focus on food storage as residential mobility decreased. There is also an increase over time in indeterminate features and vegetation anomalies during this same time period.

Higher occupation density identified by current project, particularly during the Thule period from about 1200 to 500 years ago, suggests that the settlements at Cape Krusenstern may be more comparable in size and density to those at other large coastal settlements in the Bering Strait region (e.g. Cape Espenberg, Wales, and Point Hope) than previously thought. Prior researchers (Giddings and Anderson 1986; Mason 1998:278) identified the occupation between about 1850 and 1300 years ago, associated with Ipiutak culture, as the densest occupation at Krusenstern, although Giddings and Anderson provide somewhat unclear interpretations of population data during the Ipiutak and later 
Thule period (e.g. Giddings and Anderson 1986: 107 versus 149). Hypotheses about regional socioeconomic interactions over the last 2000 years (Mason 1998; Sheehan 1985, 1995, 1997) should be reevaluated in light of these new data. Of particular interest is how patterns of mobility and related spheres of economic and political interaction may have changed as people lived for much longer periods of time on the coast. As people became more sedentary did their interaction spheres contract? New data from Cape Krusenstern also lends support to the idea that high population density and competition for resources among coastal settlements situated in resource-rich locations may have driven a movement of people into the interior of northwest Alaska beginning around $800 \mathrm{cal}$ BP (Mason and Barber 2003). While it is clear from the current study that local population declined, more data on regional population levels are needed to further evaluate this hypothesis. This coincides with the timing of a Neoeskimo migration wave into the Eastern Arctic that may have been motivated by population pressure in the western Arctic (Friesen and Arnold 2008; McGhee 2000, 2009; Morrison 2009).

New data show that occupation of the site complex over the last 2000 years was nearly continuous. Although occupation density has shifted over time, people persisted in their use of this coastal landscape for thousands of years. This is despite significant periods of late Holocene environmental variability (e.g. Bigelow and Powers 2001; Bird, et al. 2009; D'Arrigo, et al. 2005; Jordan 2009:19; Mason and Barber 2003:84). A period of Neoglacial cooling is indicated by various regional paleoenvironmental proxies between about 4000 and 1000 cal BP, followed by warming, perhaps related to the broader Medieval Climatic Optimum, between about 1000 and 300 cal BP (Bird, et al. 2009; Calkin, et al. 1998; D'Arrigo, et al. 2005; Ellis and Calkin 1984; Ellis, et al. 1981; Graumlich and King 1997; Mann, et al. 2002; Mason and Jordan 1993). Between about 300 cal BP and the mid-1800s, Little Ice Age - cooling prevailed. Proxies across the Arctic indicate warming after the mid-1800s (Overpeck, et al. 1997). Minimally, persistent occupation of this coastal landscape suggests long-term cultural resilience in a changing environment. While technology and subsistence activities change significantly 
over the last 4200 years, once people began to live on the coast in permanent or semi-permanent settlements they persisted in doing so despite significant environmental changes. Alternatively, it is possible that impacts of late Holocene environmental change on people may have been of a lesser magnitude than previously thought. On-going research directed at refining the paleoenvironmental reconstruction for Cape Krusenstern will be important in further exploring these issues.

\section{Conclusions}

While survey results indicate much higher local population than was identified by prior work, our results overall further support the patterns established by Giddings and Anderson of more permanent or sedentary coastal occupation beginning about 2800 years ago and increasingly significantly after 2000 years ago. Sites dated to before 2000 years ago merit additional investigation. Direct dates obtained for the earliest occupations at the site complex are an important addition to a handful of reliable radiocarbon dates for coastal occupation before 3000 years ago. These dates suggest that people occupied coastal land forms like Cape Krusenstern soon after they developed. While rising sea-level may have obscured older sites it is also possible that shoreline progradation after 5000 years ago was a key factor in creating more favorable coastal habitats that led to increased marine resource use.

This work contributes new dates and data to the debate over the timing and character of maritime adaptations north of the Bering Strait and identifies several areas for additional research. Sustained occupation of the coast through several periods of increased environmental variability point to the resilience of coastal foragers with a committed maritime economy, even in challenging high latitude environments. New paleoenvironmental data and additional archaeological research are needed to further explore the coastal settlement patterns identified here, but this work provides a strong framework for future study of coastal adaptations and human-environment interactions. 


\section{Acknowledgements}

This research was funded by the National Park Service through a cooperative agreement (J8W07070032) managed the Pacific Northwest Cooperative Ecosystem Study Unit. Many thanks to Douglas D. Anderson, Eileen Devinney, Robert Gal, and Ben Fitzhugh for their contributions to this research. This paper was much improved by comments from Virginia Butler, Ross Smith, and Amanda Taylor on earlier drafts, as well as comments by three anonymous reviewers. William Brown assisted with calibrating radiocarbon data and creating probability sum distributions. All errors and omissions are the responsibility of the authors. 


\section{References Cited}

Ackerman, R. E. 1998. Early maritime traditions in the Bering, Chukchi, and East Siberian seas. Arctic Anthropology 35(1):247-262.

Aigner, J. S. 1976. Early Holocene evidence for the Aleut maritime adaptation. Arctic Anthropology 13(2):32-45.

Ames, K. M. 1994. The Northwest Coast: Complex hunter-gatherers, ecology, and social evolution. Annual Review of Anthropology 23:209-229.

Ames, K.M. 2000. Review of Archaeological Data. In Kennewick Man: Cultural Affiliation Report. Washington D.C.: National Park Service.

Anderson, D. D. 1972. An archaeological survey of the Noatak Drainage, Alaska. Arctic Anthropology 9(1):66-117.

Anderson, D. D. 1977. Archaeological Surveys of the Proposed Cape Krusenstern and Kobuk National Monuments. Providence: Brown University Department of Anthropology.

Anderson, D. D. 1984. Prehistory of North Alaska. In Handbook of North American Indians: Arctic (D. Damas, ed.): 80-93. Washington D.C.: Smithsonian Institution Press.

Anderson, D. D. 1988. Onion Portage: The archaeology of a stratified site from the Kobuk River, Northwest Alaska. Anthropological Papers of the University of Alaska 22(1):1-163.

Anderson, D. D., and W. W. Anderson. 1977. Prehistoric and Early Historic Human Settlements and Resource Use Areas in the Selawik Drainage, Alaska. Providence: Brown University Department of Anthropology.

Anderson, S.L. and A. K. Freeburg. In press. A high resolution chronology for the Cape Krusenstern site complex, northwest Alaska. Arctic Anthropology 50(1).

Bigelow, N. H., and W. R. Powers. 2001. Climate, vegetation, and archaeology $14,000-9000$ cal yr B.P. in Central Alaska. Arctic Anthropology 38(2):171-195.

Bird, B., M. B. Abbott, B. P. Finney, and B. Kutchko. 2009. A 2000 year varve-based climate record from the central Brooks Range, Alaska. Journal of Paleolimnology 41:25-41.

Bronk Ramsey, C. 2009. Bayesian analysis of radiocarbon dates. Radiocarbon 51(1):337-360.

Calkin, P. E., D. S. Kaufman, B. J. Przybyl, W. B. Whitford, and B. J. Peck. 1998. Glacier regimes, periglacial landforms, and Holocene climate change in the Kigluaik Mountains, Seward Peninsula, Alaska, U.S.A. Arctic and Alpine Research 30(2):154-165.

Conolly, J., and M. Lake. 2006. Geographical Information Systems in Archaeology. Cambridge: Cambridge University Press. 
D'Arrigo, R., E. Mashig, D. Frank, D. Wilson, and G. Jacoby. 2005. Temperature variability over the last millenium inferred from Northwestern Alaska tree rings. Climate Dynamics 24:227-236.

Darwent, C. M. 2006. Reassessing the Old Whaling locality at Cape Krusenstern. In Dynamics of Northern Societies Proceedings of the SILA/NABO Conference on Arctic and North Atlantic Archaeology, Copenhagen, May 10th-14th 2004 (J. Arneborg and B. Grønnow, eds.): 95-101. Copenhagen: Publications from the National Museum.

Darwent, J., and C. M. Darwent. 2005. Occupational history of the Old Whaling Site at Cape Krusenstern, Alaska. Alaska Journal of Anthropology 3(2):135-154.

Ellis, J. M., and P. E. Calkin. 1984. Chronology of Holocene glaciation, central Brooks Range, Alaska. Geological Society of America Bulletin 95(8):897-912.

Ellis, J. M., T. D. Hamilton, and P. E. Calkin. 1981. Holocene glaciation of the Arrigetch Peaks, Brooks Range, Alaska. Arctic 34(2):158-168.

Erlandson, J. M. 2001. The archaeology of aquatic adaptations: paradigms for a new millenium. Journal of Archaeological Research 9(4):287-350.

Erlandson, J. M., and T. J. Braje. 2011. From Asia to the Americas by boat? Paleogeography, paleoecology, and stemmed points of the northwest Pacific. Quaternary International 239(1-2):28-37.

Erlandson, J. M., M. H. Graham, B. J. Bourque, D. Corbett, J. A. Estes, and R. S. Steneck. 2007. The kelp highway hypothesis: marine ecology, the coastal migration theory, and the peopling of the Americas. Journal of Island and Coastal Archaeology 2(2):161-174.

Erlandson, J. M., and M. L. Moss. 1999. The systematic use of radiocarbon dating in archaeological surveys in coastal and other erosional environments. American Antiquity 64(3):431-443.

Erlandson, J. M., M. L. Moss, and M. Des Lauriers. 2008. Life on the edge: early maritime cultures of the Pacific Coast of North America. Quaternary Science Reviews 27(23-24):2232-2245.

Erlandson, J. M., and T. C. Rick. 2010. Archaeology meets marine ecology: the antiquity of maritime cultures and human impacts on marine fisheries and ecosystems. Annual Review of Marine Science 2:231-251.

Erlandson, J. M., T. C. Rick, T. J. Braje, M. Casperson, B. Culleton, B. Fulfrost, T. Garcia, D. A. Guthrie, N. Jew, D. J. Kennett, M. L. Moss, L. Reeder, C. Skinner, J. Watts, and L. Willis. 2011. Paleoindian seafaring, maritime technologies, and coastal foraging on California's Channel Islands. Science 331(6021):11811185.

Fitzhugh, B. 2003. The Evolution of Complex Hunter-Gatherers: Archaeological Evidence from the North Pacific. New York: Kluwer Academic/Plenum Publishers.

Fitzhugh, B. in review. The origins and development of arctic maritime adaptations in the Western Subarctic. In The Oxford Handbook of Arctic Archaeology (T.M. Friesen and O.K. Mason, eds.). Oxford: Oxford University Press. 
Friesen, T. M., and C. D. Arnold. 2008. The timing of the Thule migration: new dates from the western Canadian Arctic. American Antiquity 73(3):527-538.

Freeburg, A. K. and S.L. Anderson. 2012. 200 Generations on the Beach of Their Tim: HumanEnvironmental Dynamics at Cape Krusenstern, Final Report. Seattle: University of Washington.

Giddings, J. L. 1938. Recent tree-ring work in Alaska. Tree-Ring Bulletin 7:10-14.

Giddings, J. L. 1940. The application of tree-ring work in Alaska. Tree-Ring Bulletin 5:16.

Giddings, J. L. 1941. Dendrochronology in Northern Alaska. University of Arizona Bulletin 12:24.

Giddings, J. L. 1942. Dated sites on the Kobuk River. Tree-Ring Bulletin 9:1.

Giddings, J. L. 1948. Chronology of the Kobuk-Kotzebue sites. Tree-Ring Bulletin 14:26-32.

Giddings, J. L. 1951. The Denbigh Flint Complex. American Antiquity 16(3):193-203.

Giddings, J. L. 1952a. The Arctic Woodland Culture of the Kobuk River. Philadelphia: University of Pennsylvania.

Giddings, J. L. 1952b. Driftwood and problems of Arctic Sea currents. Proceedings of the American Philosophical Society 96(2):129-142.

Giddings, J. L. 1957. Round houses in the Western Arctic. American Antiquity 23(2):121-135.

Giddings, J. L. 1961. Kobuk River People. Fairbanks: University of Alaska

Giddings, J. L. 1964. The Archaeology of Cape Denbigh. Providence: Brown University Press.

Giddings, J. L. 1966. Cross-dating the archeology of northwestern alaska. Science 153(3732):127-35.

Giddings, J. L. 1967. Ancient Men of the Arctic. New York: Knopf.

Giddings, J. L., and D. D. Anderson. 1986. Beach Ridge Archeology of Cape Krusenstern: Eskimo and PreEskimo Settlements Around Kotzebue Sound, Alaska. Washington, D.C.: National Park Service.

Graumlich, L., and J. C. King. 1997. Late Holocene Climatic Variation in Northwestern Alaska as Reconstructed from Tree Rings. Tucson: University of Arizona.

Harritt, R. K. 1994. Eskimo Prehistory on the Seward Peninsula. Anchorage: National Park Service.

Hopkins, D. M. 1977. Coastal Processes and Coastal Erosional Hazards to the Cape Krusenstern Archaeological Site. Menlo Park: U.S. Department of the Interior Geological Survey.

Jordan, J. W. 2009. Arctic climate and landscape ca. AD 800-1400. In The Northern World AD 900-1400 (H. Maschner, O.K. Mason, and R. McGhee, eds.):7-29. Salt Lake City: University of Utah Press. 
Jordan, J. W., and O. K. Mason. 1999. A 5000-year record of intertidal peat stratigraphy and sea level change from northwest Alaska. Quaternary International 60:37-47.

Larsen, H., and F. G. Rainey. 1948. Ipiutak and the Arctic Whale Hunting Culture. New York: American Museum of Natural History.

Laughlin, W. S., and J. S. Aigner. 1966. Preliminary analysis of the Anangula unifacial core and blade industry. Arctic Anthropology 3(2):41-56.

Louderback, L. A., D. K. Grayson, and M. Llobera. 2011. Middle-holocene climates and human population densities in the Great Basin, western USA. Holocene 21(2):366-373.

Manley, W.F. 2007. High-resolution orthorectified Imagery for the Coastal Areas of Bering Land Bridge National Park and Cape Krusenstern National Monument, Northwest Alaska. Fairbanks: National Park Service, Arctic Network Inventory and Monitoring Program.

Mann, D. H., P. A. Heiser, and B. P. Finney. 2002. Holocene history of the Great Kobuk Sand Dunes, Northwestern Alaska. Quaternary Science Reviews 21(4-6):709.

Mason, O. K. 1998. The contest between the Ipiutak, Old Bering Sea, and Birnirk polities and the origin of whaling during the first millennium A.D. along Bering Strait. Journal of Anthropological Archaeology 17(3):240-325.

Mason, O. K. 2009a. Flight from the Bering Strait: Did Siberian Punuk/Thule military cadres conquer northwest Alaska? In The Northern World AD 900-1400 (H. Maschner, O.K. Mason, and R. McGhee, eds.):76-128. Salt Lake City: The University of Utah Press.

Mason, O. K. 2009b. "The multiplication of forms:" Bering Strait harpoon heads as a demic and macroevolutionary proxy. In Macroevolution in Human Prehistory (A.M. Prentiss, ed.): 73-107. New York: Springer.

Mason, O. K., and V. Barber. 2003. A paleo-geographic preface to the origins of whaling: Cold is better. In Indigenous Ways to the Present: Native Whaling in the Western Arctic (A.P. McCartney, ed.): 69-108. Edmonton and Salt Lake City: Canadian Circumpolar Institute Press and the University of Utah Press.

Mason, O. K., and P. M. Bowers. 2009. The origin of Thule is always elsewhere: Early Thule within Kotzebue Sound, "cul-de-sac" or nursery? In On the Track of the Thule Culture from Bering Strait to East Greenland. Proceedings of the SILA Conference "The Thule Culture - New Perspectives in Inuit Prehistory" Copenhagen Oct 26th $-28^{\text {th }}$ (B. Gronnow, ed.): 25-44. Copenhagen: Publications from the National Museum.

Mason, O. K., and J. W. Jordan. 1993. Heightened North Pacific storminess and synchronous late Holocene erosion of Northwest Alaska beach ridge complexes. Quaternary Research 40(1):55-69.

Mason, O. K., and J. W. Jordan. 2002. Minimal Late Holocene sea level change in the Chukchi Sea: Arctic insensitivity to global change? Global and Planetary Change 32(1):13-23. 
Mason, O. K., J. W. Jordan, and L. Plug. 1995. Late Holocene storm and sea-level history in the Chukchi Sea. Journal of Coastal Research 17:173-180.

Mason, O. K., and S. L. Ludwig. 1990. Resurrecting beach ridge archaeology: Parallel depositional records from St.Lawrence Island and Cape Krusenstern. Geoarchaeology 5(4):349-373.

McClenahan, P. L., and D. E. Gibson. 1990. Cape Krusenstern National Monument: an Archeological Survey. Anchorage:National Park Service.

McGhee, R. 2000. Radiocarbon dating and the timing of the Thule migration. In Identities and Cultural Contacts in the Arctic: Proceedings from a Conference at the Danish National Museum, Copenhagen, November 30 to December 2, 1999 (M. Appelt, J. Berglund, and H.C. Gullov, eds.): 81-191. Copenhagen: Publications from the National Museum.

McGhee, R. 2009. When and why did the Inuit move to the Eastern Arctic? In The Northern World AD 900-1400 (H. Maschner, O.K. Mason, and R. McGhee, eds.): 155-163. Salt Lake City: University of Utah Press.

Meitl, S. J. 2008. Timing and Resolution of Denbigh Occupations at Onion Portage, Alaska. M.A. Thesis. Fairbanks: University of Alaska.

Moore, G. W. 1960. Recent Eustatic Sea-Level Fluctuations recorded by Arctic Beach Ridges. Washington D.C.: U.S. Government.

Moore, G. W. 1966. Arctic beach sedimentation. In Environment of the Cape Thompson Region, Alaska (N. Wilimovsky and J.N. Wolfe, eds.): 587-608. Oak Ridge: Atomic Energy Commission.

Morrison, D. 2009. The "arctic maritime" expansion: a view from the Western Canadian Arctic. In The Northern World AD 900-1400 (H. Maschner, O.K. Mason, and R. McGhee, eds.):164-178. Salt Lake City: University of Utah Press.

Odess, D. 2003. An Early Arctic Small Tool tradition structure from interior Northwestern Alaska. Études/Inuit/Studies 27(1-2):13-27.

Overpeck, J., K. Hughen, D. Hardy, R. Bradley, R. Case, M. Douglas, B. Finney, K. Gajewski, G. Jacoby, A. Jennings, S. Lamoureux, A. Lasca, G. MacDonald, J. Moore, M. Retelle, S. Smith, A. Wolfe, and G. Zielinski. 1997. Arctic environmental change of the last four centuries. Science 278:1251-1256.

Pringle, H. 2008. Signs of the first whale hunters. Science 320(5873):175.

Reimer, P., M. Baillie, E. Bard, A. Bayliss, J. Beck, P. Blackwell, C. Bronk Ramsey, C. Buck, G. Burr, R. Edwards, M. Friedrich, P. Grootes, T. Guilderson, I. Hajdas, T. Heaton, A. Hogg, K. Hughen, K. Kaiser, B. Kromer, F. McCormac, S. Manning, R. Reimer, D. Richards, J. Southon, S. Talamo, C. Turney, J. van der Plicht, and C. Weyhenmeyer. 2009. IntCal09 and Marine09 radiocarbon age calibration curves, 50,000 years cal BP. Radiocarbon 51(4):1111-1150.

Rowley-Conwy, P. 1999. Introduction: human occupation of the Arctic. World Archaeology: Arctic Archaeology 30(3):349-353. 
Schaaf, J. M. 1988. The Bering Land Bridge: An Archaeological Survey. Anchorage: National Park Service.

Sheehan, G. W. 1985. Whaling as an organizing focus in northwestern Alaskan Eskimo societies. In Prehistoric Hunter-Gatherers:the Emergence of Cultural Complexity (T.D. Price and J.A. Brown, eds.): 123-154. New York: Academic Press, Inc.

Sheehan, G. W. 1995. Whaling surplus, trade, war, and the integration of prehistoric northern and northwestern Alaskan economies, A.D. 1200-1826. In Hunting the Largest Animals: Native Whaling in the Western Arctic and Subarctic (A.P. McCartney, ed.): 185-206. Edmonton: Canadian Circumpolar Institute Press.

Sheehan, G. W. 1997. In the Belly of the Whale. Anchorage: Alaska Anthropological Association.

Surovell, T. A., and P. J. Brantingham. 2007. A note on the use of temporal frequency distributions in studies of prehistoric demography. Journal of Archaeological Science 34(11):1868-1877.

Surovell, T. A., J. Byrd Finley, G. M. Smith, P. J. Brantingham, and R. Kelly. 2009. Correcting temporal frequency distributions for taphonomic bias. Journal of Archaeological Science 36(8):1715-1724.

Williams, A. N. 2012. The use of summed radiocarbon probability distributions in archaeology: a review of methods. Journal of Archaeological Science 39(3):578-589.

Witze, A. 2008. Whaling scene found in 3,000-year-old picture. Nature online. http://www.nature.com/news/2008/080331/full/news.2008.714.html

Yesner, D. R. 1998. Origins and development of maritime adaptations in the Northwest Pacific region of North America: A zooarchaeological perspective. Arctic Anthropology 35(1):204-222.

Zimmerman, G. 1981. Feature detection through the utilization of aerial photographs: Cape Krusenstern, Alaska. Anchorage: National Park Service. 


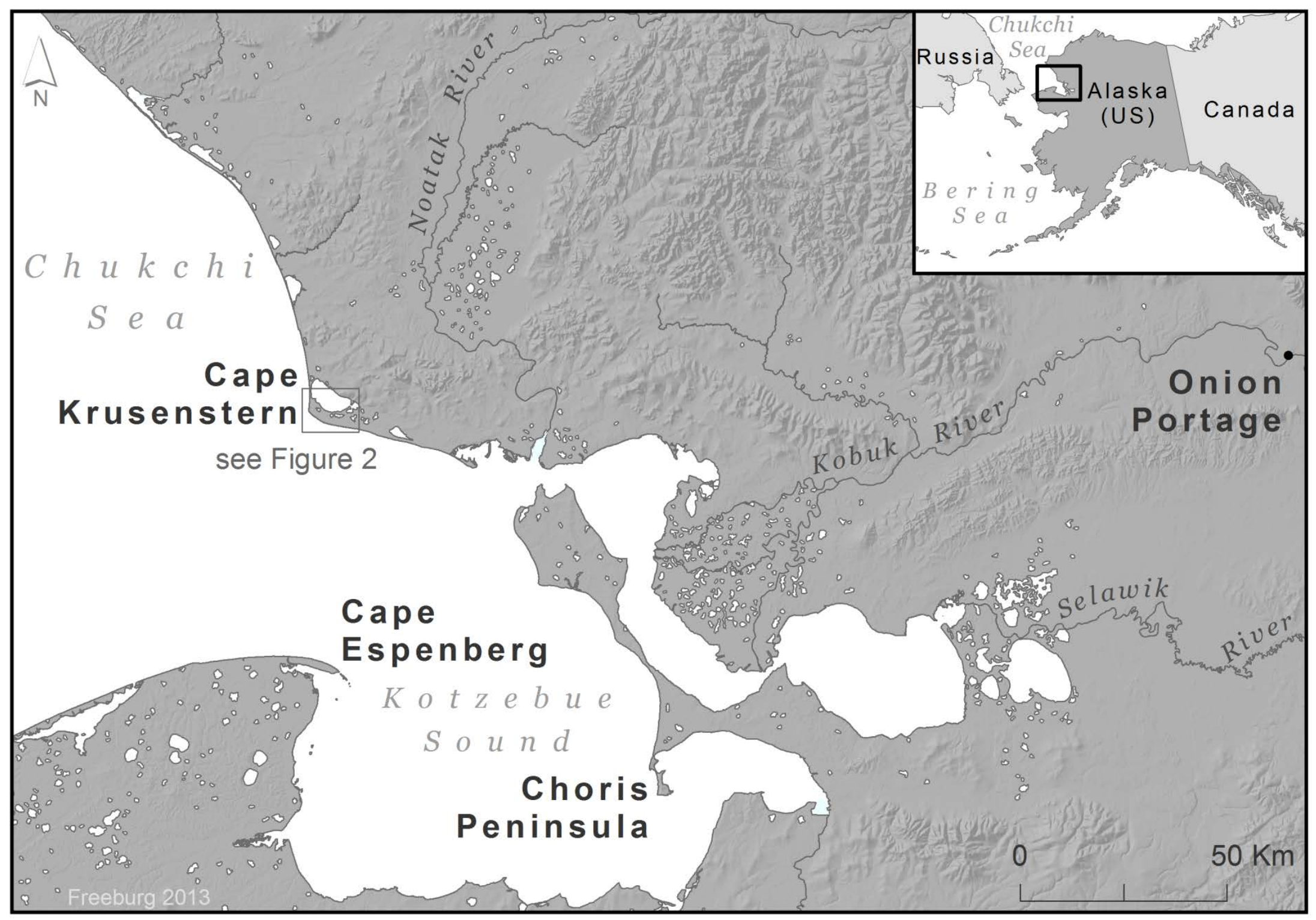

Figure 1. Location of Cape Krusenstern archaeological site complex in northwest Alaska. 


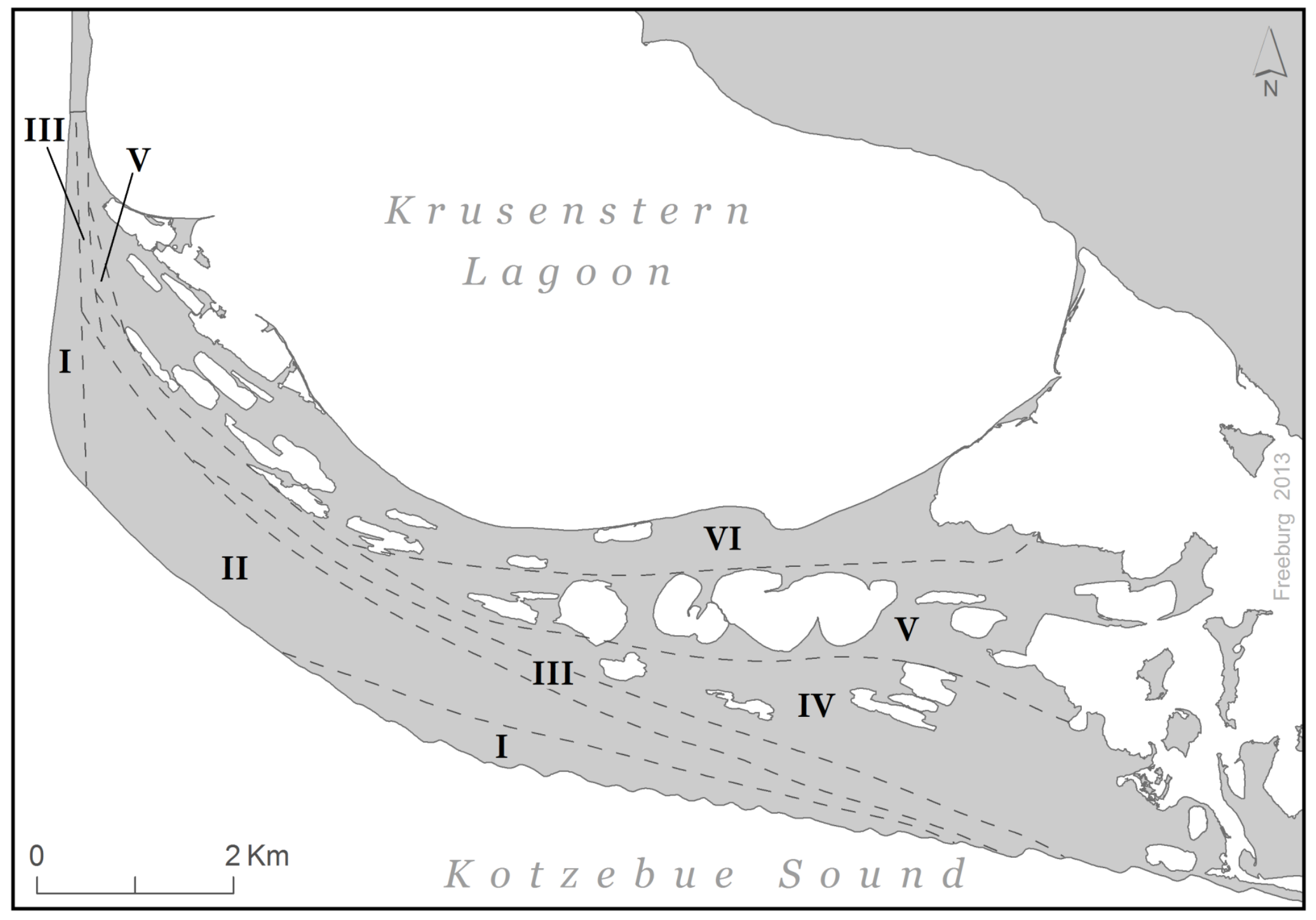

Figure 2. Beach ridge sequence at Cape Krusenstern. 


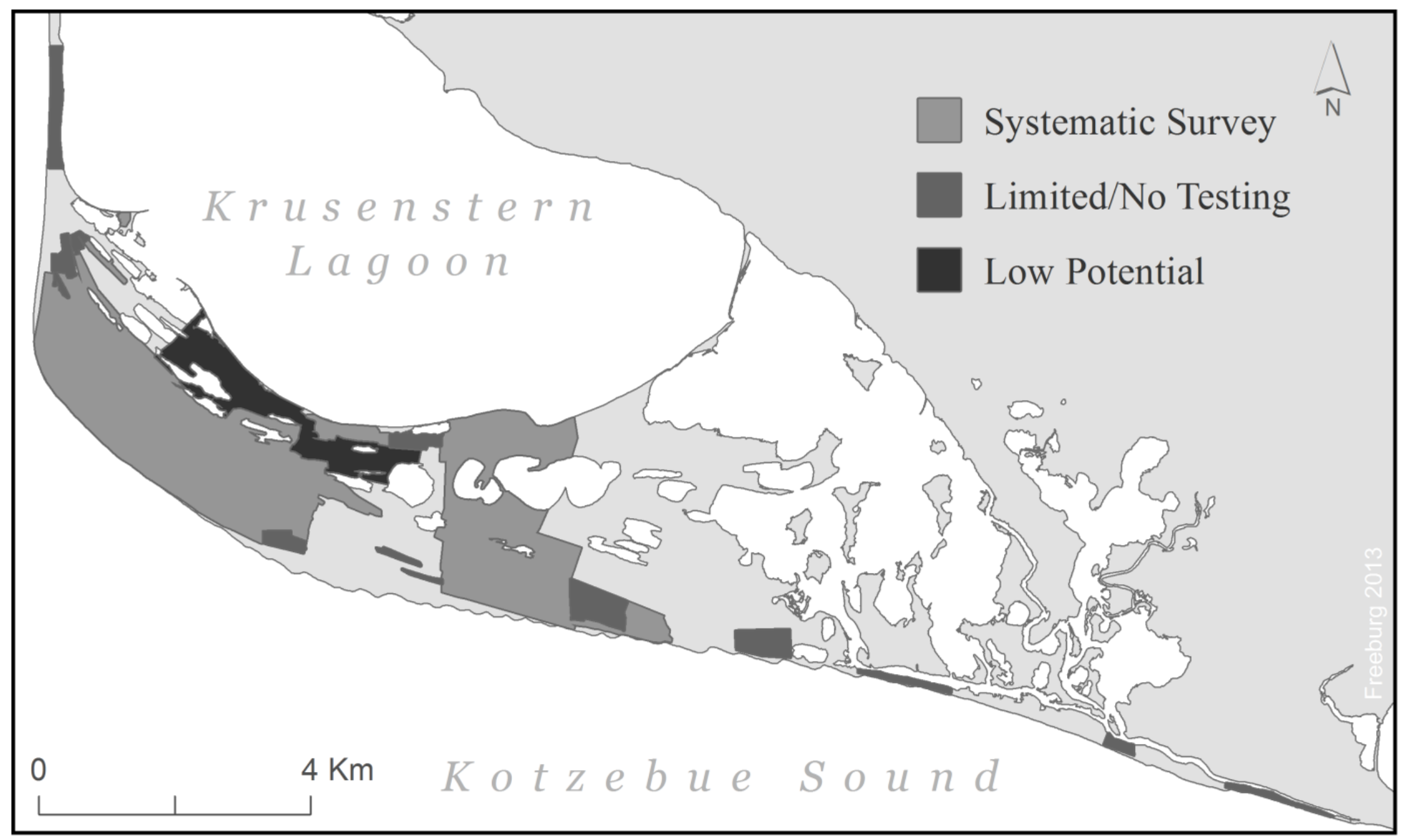

Figure 3. Areas surveyed by project. 


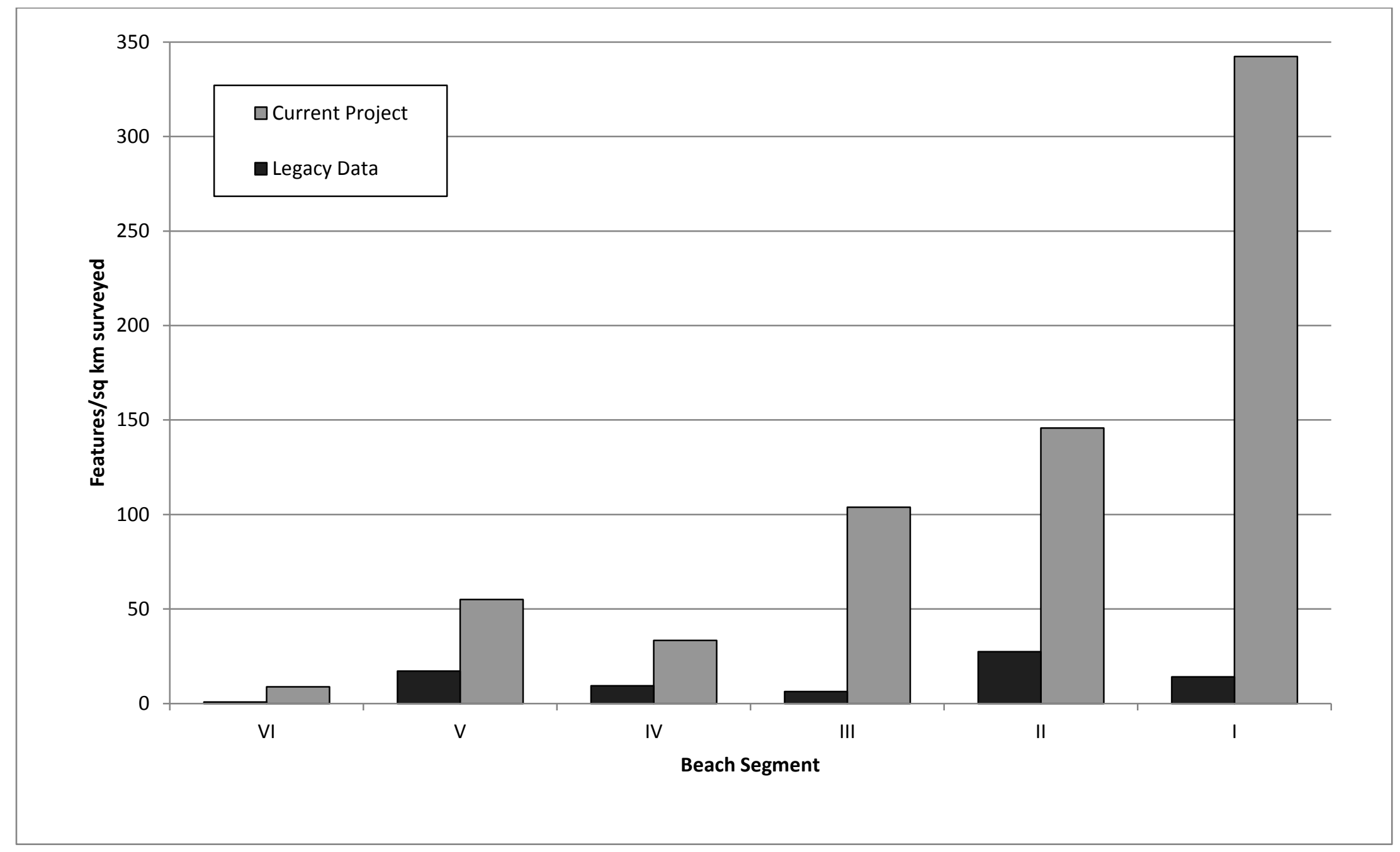

Figure 4. Comparison of features per square km identified by the current project and by prior investigations in the current project survey area. 


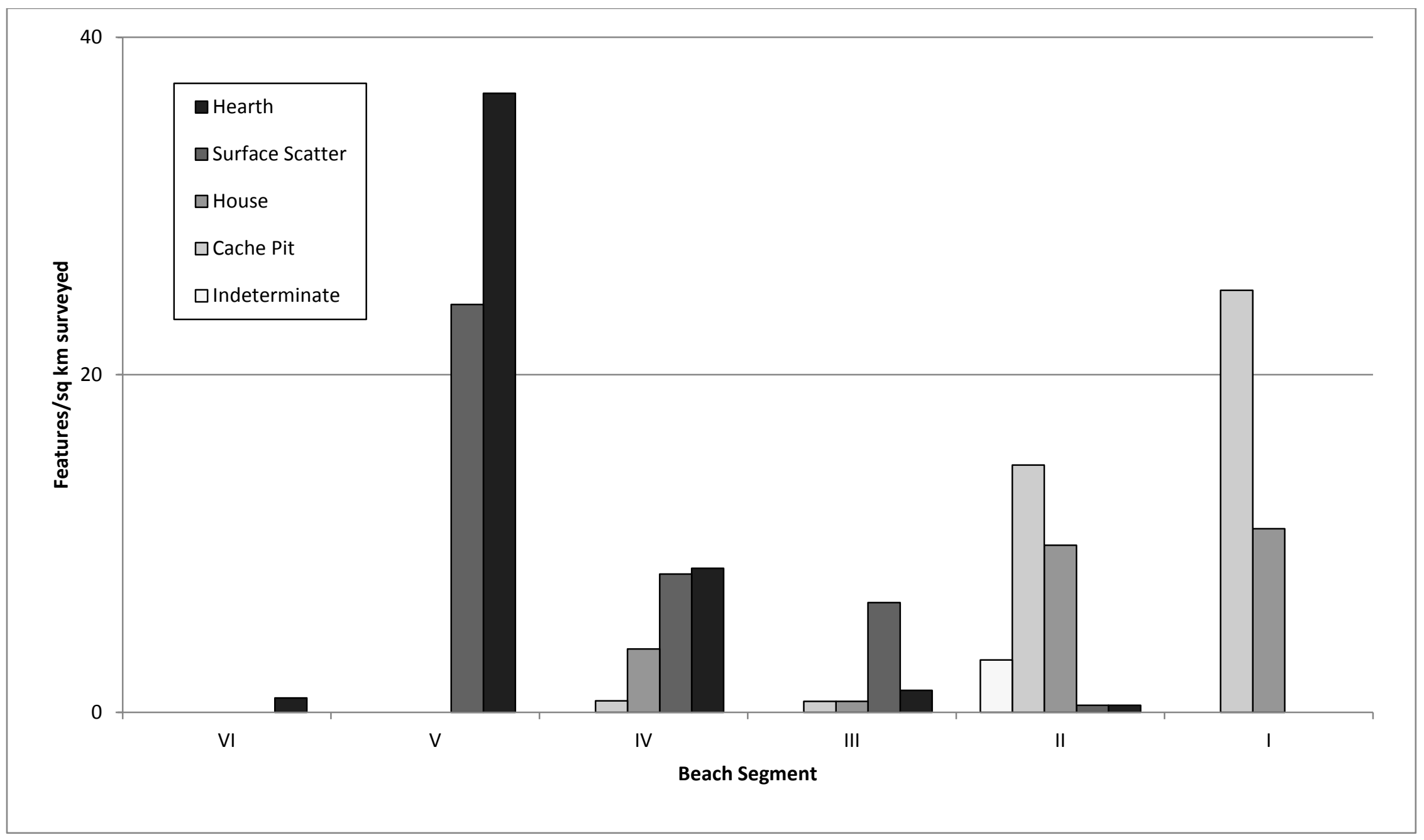

Figure 5. Legacy features reported in the current project area. 
Anderson and Freeburg

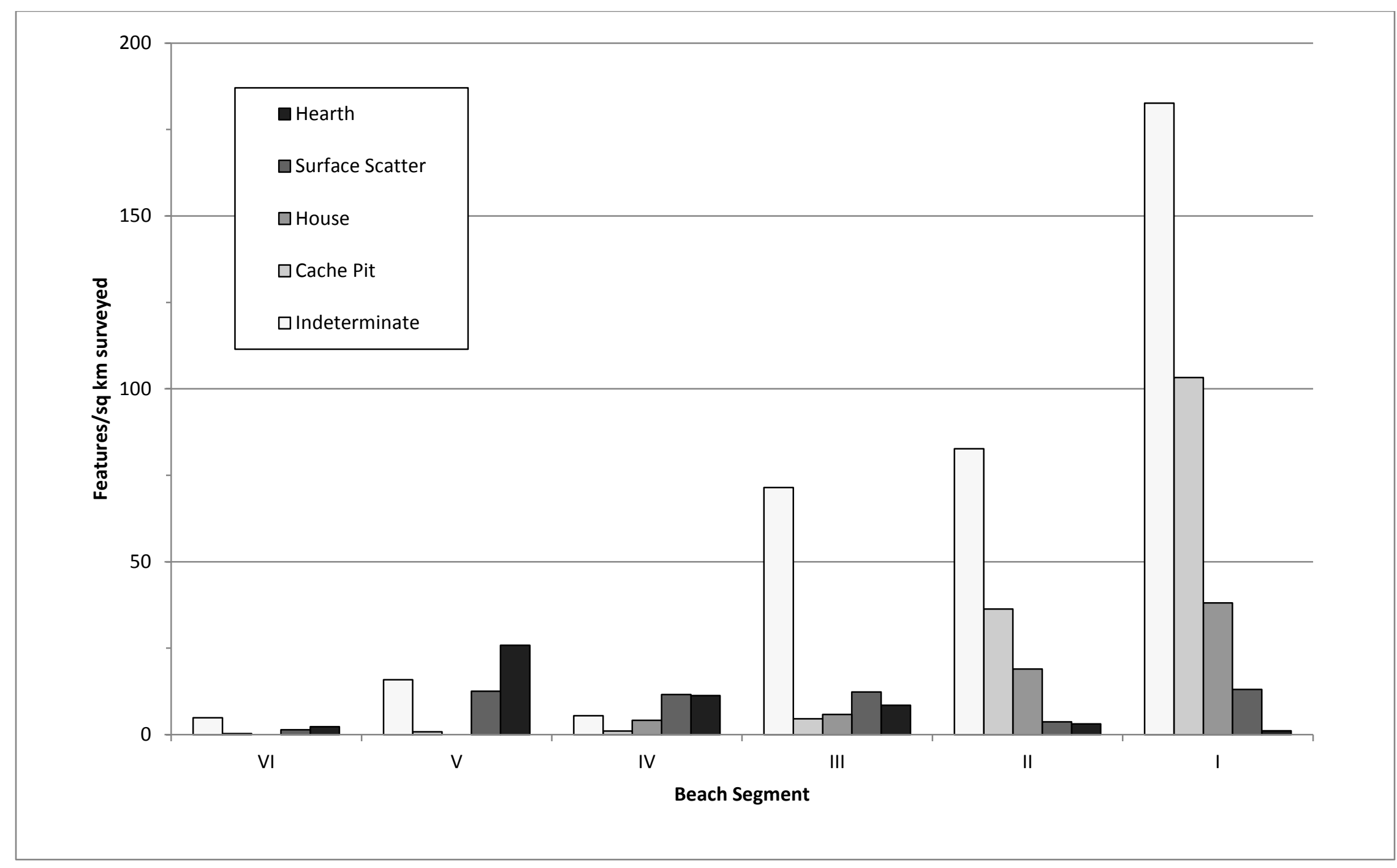

Figure 6. Features identified by current project. 


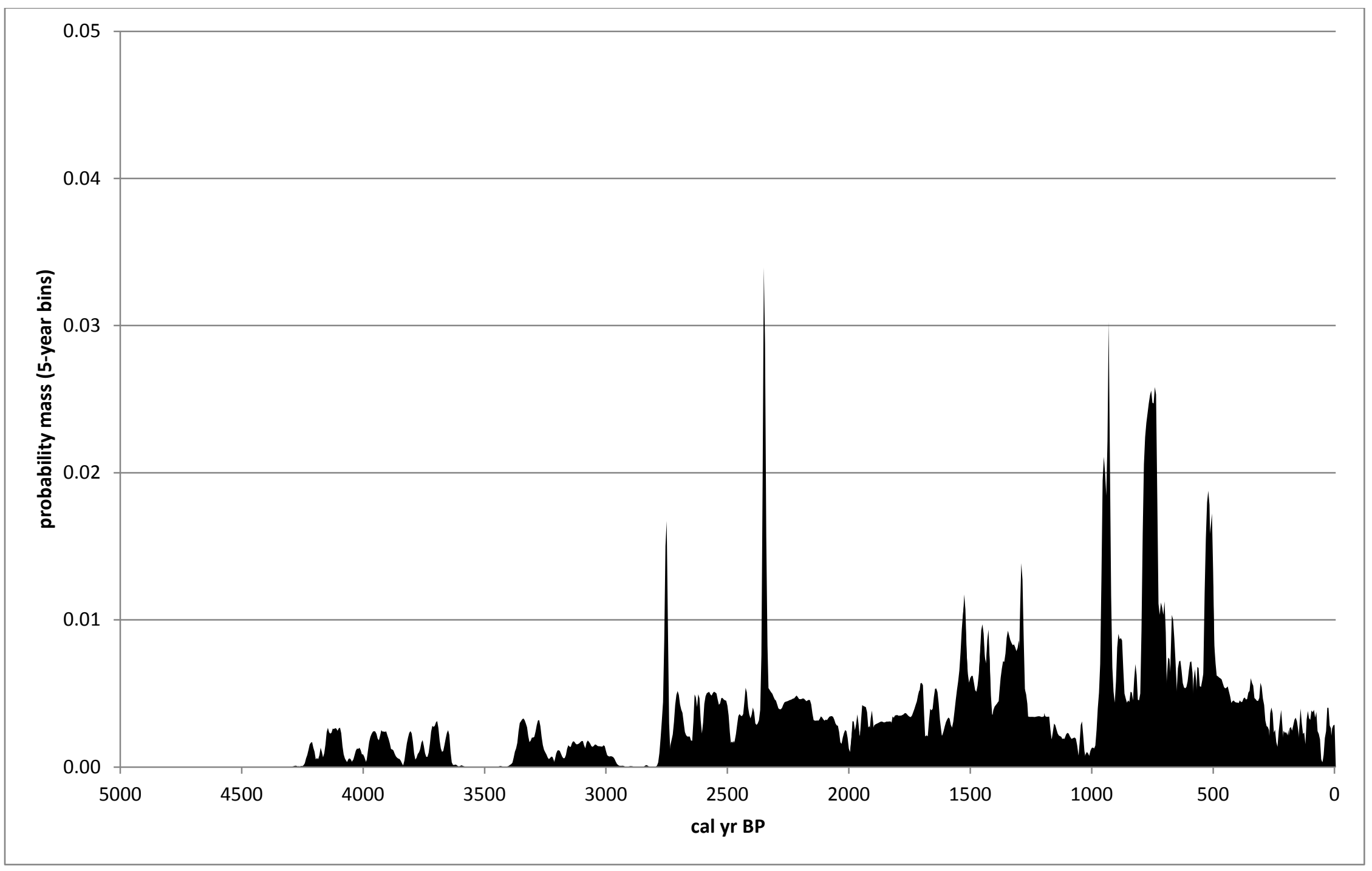

Figure 7. Summed probability plot of all new dates. 

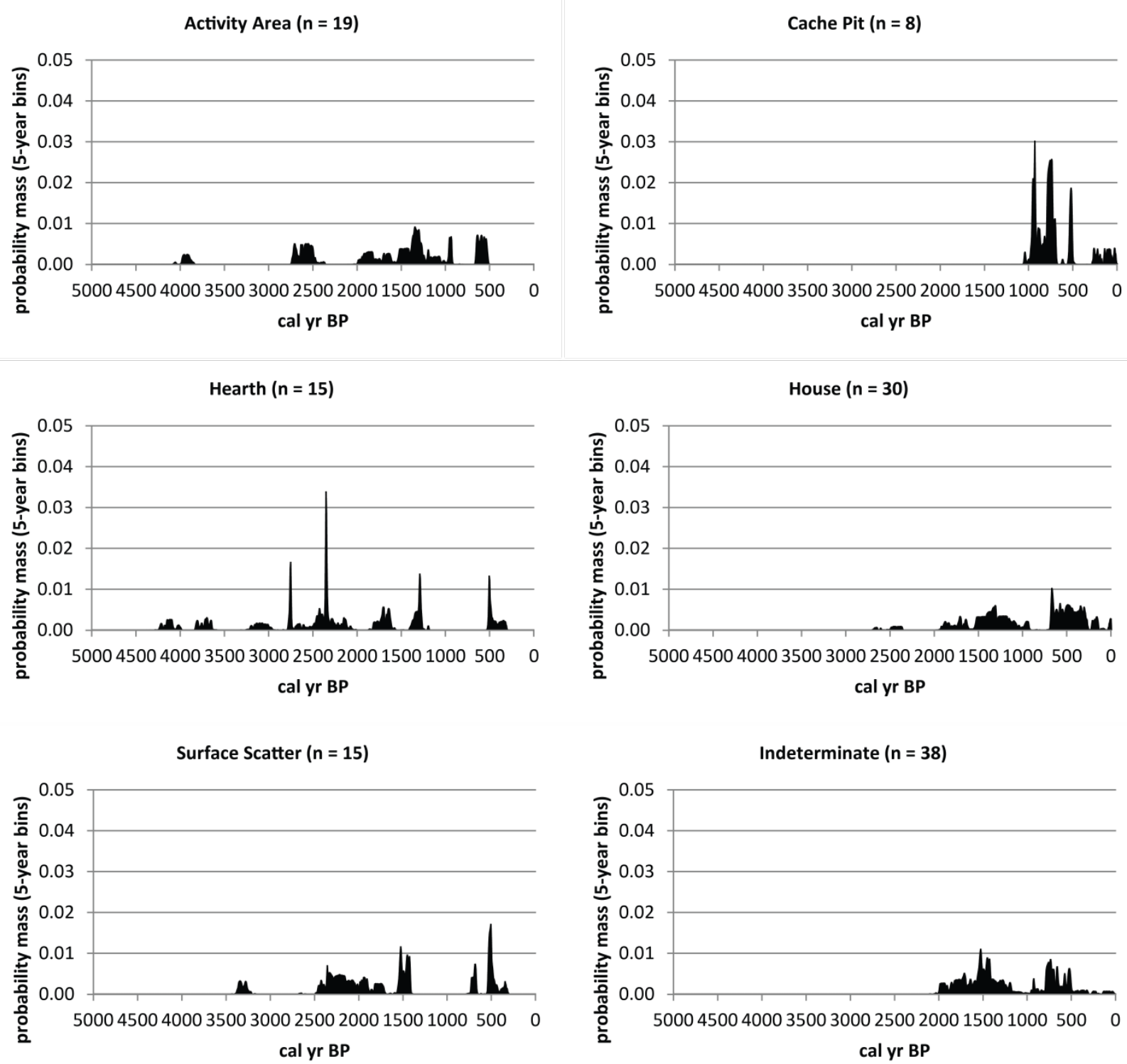

Figure 8. Summer probability plots for new dates sorted by feature. 
Table 1. Legacy and new beach segment age ranges.

\begin{tabular}{|c|c|c|c|c|}
\hline \multirow{2}{*}{$\begin{array}{c}\text { Beach } \\
\text { segment }\end{array}$} & \multirow{2}{*}{$\begin{array}{c}\text { Pre-Project Approximate } \\
\text { Age Ranges }\end{array}$} & \multicolumn{2}{|c|}{ New Upper Limiting Date } & \multirow{2}{*}{$\begin{array}{c}\text { Archaeological Culture } \\
\text { Attributions }{ }^{1}\end{array}$} \\
\hline & & $\begin{array}{c}\text { Conventional } \\
\text { Radiocarbon Age }\end{array}$ & $\begin{array}{c}\text { Two Sigma Calibrated } \\
\text { Age Range (BP) }\end{array}$ & \\
\hline VI & $4200-3600 \mathrm{BP}^{1}$ & $3760 \pm 35$ & $4238-3990$ & Classic Denbigh \\
\hline V & $3600-3100 \mathrm{BP}^{1}$ & $3620 \pm 30$ & $4068-3842$ & $\begin{array}{l}\text { Classic - Late Denbigh, Early } \\
\text { Choris }\end{array}$ \\
\hline IV & $3100-2500 \mathrm{BP}^{1,2}$ & $2930 \pm 40$ & $3215-2958$ & Old Whaling, Choris \\
\hline III & $2500-2000 \mathrm{BP}^{1}$ & $2630 \pm 25$ & $2780-2735$ & Norton-Near Ipiutak \\
\hline II & $1900\left(1750^{3}\right)-1000 \mathrm{BP}$ & $1980 \pm 25$ & $1990-1880$ & Ipiutak, Birnirk, Thule \\
\hline 1 & $1000-$ present $^{1}$ & $1030 \pm 25$ & $1045-918$ & $\begin{array}{l}\text { Thule, Kotzebue, Historic } \\
\text { Inupiat }\end{array}$ \\
\hline
\end{tabular}

\footnotetext{
${ }^{1}$ Giddings and Anderson 1986
}

${ }^{2}$ Darwent and Darwent (2005) report two sigma age ranges between 3138 and 2742, but interpret the site occupation to have been between ca. 2900 and 2700 BP.

${ }^{3}$ Mason 2009

${ }^{4}$ Calibrated with OxCal 4.1 (Bronk Ramsey 2009a) IntCal09 (Reimer et al. 2009). 
Anderson and Freeburg

Table 2. Legacy feature counts for entire beach ridge complex

\begin{tabular}{lcccccccc}
\hline Feature Type & I & II & III & IV & V & VI & Unknown & Total \\
\hline Hearth & 0 & 2 & 4 & 35 & 70 & 10 & 12 & $\mathbf{1 3 3}$ \\
Cache Pit & 79 & 106 & 3 & 3 & 0 & 0 & 2 & $\mathbf{1 9 3}$ \\
House & 25 & 57 & 1 & 11 & 0 & 0 & 7 & $\mathbf{1 0 1}$ \\
Surface Scatter & 0 & 2 & 15 & 34 & 59 & 0 & 2 & $\mathbf{1 1 2}$ \\
Burial & 4 & 15 & 1 & 1 & 0 & 0 & 1 & $\mathbf{2 2}$ \\
Indeterminate & & & & & & & & \\
Type & 2 & 18 & 2 & 0 & 0 & 0 & 11 & $\mathbf{3 3}$ \\
Campsite & 3 & 2 & 1 & 1 & 0 & 0 & 0 & $\mathbf{7}$ \\
Midden* & 0 & 11 & 0 & 4 & 0 & 0 & 0 & $\mathbf{1 5}$ \\
Unknown Type & 1 & 2 & 0 & 5 & 6 & 4 & 5 & $\mathbf{2 3}$ \\
Total & $\mathbf{1 1 4}$ & $\mathbf{2 1 5}$ & $\mathbf{2 7}$ & $\mathbf{9 4}$ & $\mathbf{1 3 5}$ & $\mathbf{1 4}$ & $\mathbf{4 0}$ & $\mathbf{6 3 9}$ \\
\hline
\end{tabular}

Table 3. Legacy feature counts for within the current project survey area

\begin{tabular}{lcccccccc}
\multicolumn{10}{c}{ Beach Segment } \\
\hline Feature Type & I & II & III & IV & V & VI & Unknown & Total \\
\hline Hearth & 0 & 2 & 2 & 25 & 44 & 3 & 0 & $\mathbf{7 6}$ \\
Cache Pit & 23 & 71 & 1 & 2 & 0 & 0 & 0 & $\mathbf{9 7}$ \\
House & 10 & 48 & 1 & 11 & 0 & 0 & 0 & $\mathbf{7 0}$ \\
Surface Scatter & 0 & 2 & 10 & 24 & 29 & 0 & 1 & $\mathbf{6 6}$ \\
Burial & 2 & 13 & 0 & 1 & 0 & 0 & 1 & $\mathbf{1 7}$ \\
Indeterminate & & & & & & & & \\
Type & 0 & 15 & 0 & 0 & 0 & 0 & 0 & $\mathbf{1 5}$ \\
Campsite & 0 & 1 & 1 & 1 & 0 & 0 & 0 & $\mathbf{3}$ \\
Midden* & 0 & 6 & 0 & 2 & 0 & 0 & 1 & $\mathbf{9}$ \\
Unknown Type & 1 & 1 & 0 & 3 & 0 & 2 & 1 & $\mathbf{8}$ \\
Total & $\mathbf{3 6}$ & $\mathbf{1 5 9}$ & $\mathbf{1 5}$ & $\mathbf{6 9}$ & $\mathbf{7 3}$ & $\mathbf{5}$ & $\mathbf{4}$ & $\mathbf{3 6 1}$ \\
\hline
\end{tabular}

*includes one feature we designated an activity area 
Table 4. Radiocarbon dates

\begin{tabular}{|c|c|c|c|c|c|c|}
\hline Accession\# & Description & $\delta^{13} \mathrm{C}(\% \circ)$ & $\begin{array}{c}\text { Conventional } \\
\text { RC Age }\end{array}$ & Age Error & $\begin{array}{l}2 \sigma \text { calibrated } \\
\text { age range }(\mathrm{BP})\end{array}$ & Feature Type \\
\hline OS-81431 & Picea & -24.45 & 540 & 30 & $634-513$ & Activity Area \\
\hline OS-81435 & Picea & -26.14 & 615 & 25 & $655-550$ & Activity Area \\
\hline OS-81442 & Salicaceae - twig & -27.26 & 625 & 25 & $660-552$ & Activity Area \\
\hline OS-81677 & Picea & -24.00 & 1030 & 25 & $1045-918$ & Activity Area \\
\hline OS-81642 & Picea & -25.11 & 1180 & 35 & $1228-982$ & Activity Area \\
\hline OS-81432 & Picea & -24.54 & 1310 & 25 & 1293-1179 & Activity Area \\
\hline OS-81427 & Picea & -25.05 & 1390 & 30 & $1349-1276$ & Activity Area \\
\hline OS-81611 & Picea & -24.25 & 1460 & 25 & $1390-1304$ & Activity Area \\
\hline OS-81283 & Picea & -25.48 & 1470 & 25 & $1398-1308$ & Activity Area \\
\hline OS-81640 & Picea & -23.95 & 1570 & 35 & $1535-1385$ & Activity Area \\
\hline Beta-223220 & Salix sp. & -26.4 & 1590 & 40 & $1558-1388$ & Activity Area \\
\hline OS-81612 & Picea & -25.45 & 1750 & 25 & $1719-1569$ & Activity Area \\
\hline OS-81639 & Picea & -23.85 & 1880 & 35 & $1891-1721$ & Activity Area \\
\hline OS-81635 & Picea & -25.34 & 1960 & 40 & $1992-1825$ & Activity Area \\
\hline OS-81610 & Picea & -23.85 & 2480 & 25 & $2717-2368$ & Activity Area \\
\hline OS-81682 & Salicaceae,cf.Salix & -25.36 & 2510 & 45 & $2745-2367$ & Activity Area \\
\hline OS-81621 & Betula & -25.98 & 2520 & 25 & 2739-2492 & Activity Area \\
\hline OS-81685 & Salicaceae, cf. Salix & -26.56 & 3620 & 30 & $4068-3842$ & Activity Area \\
\hline OS-81438 & Bark & -24.13 & 130 & 25 & 273-10 & Cache Pit \\
\hline OS-81647 & Picea & -24.43 & 490 & 35 & $622-496$ & Cache Pit \\
\hline OS-81575 & R. tarandus, mid long bone & -18.59 & 830 & 30 & $791-686$ & Cache Pit \\
\hline OS-81578 & R. tarandus, L tibia, mid & -19.52 & 840 & 25 & $790-692$ & Cache Pit \\
\hline OS-81576 & R. tarandus, distal radius. & -19.18 & 875 & 25 & $905-728$ & Cache Pit \\
\hline OS-81656 & Picea & -24.59 & 890 & 35 & $911-733$ & Cache Pit \\
\hline OS-81581 & Picea & -24.86 & 1010 & 25 & $970-802$ & Cache Pit \\
\hline Beta-226688 & Picea sp./Larix sp. & -24.8 & 1030 & 40 & $1055-800$ & Cache Pit \\
\hline OS-81653 & Picea & -25.72 & 340 & 35 & 484-309 & Hearth \\
\hline OS-81281 & Picea & -24.85 & 430 & 25 & $525-342$ & Hearth \\
\hline OS-81279 & Picea & -23.54 & 1350 & 25 & $1310-1185$ & Hearth \\
\hline Beta-226689 & Picea sp./Larix sp. & -24.2 & 1440 & 40 & 1399-1291 & Hearth \\
\hline
\end{tabular}

Page $\mathbf{3 6}$ of $\mathbf{4 0}$ 


\begin{tabular}{|c|c|c|c|c|c|c|}
\hline OS-78546 & Picea & -25.14 & 1760 & 25 & $1768-1569$ & Hearth \\
\hline Beta-226690 & Picea sp./Larix sp. & -22.9 & 1800 & 40 & $1859-1611$ & Hearth \\
\hline OS-78454 & Salicaceae & -26.17 & 2160 & 30 & $2308-2056$ & Hearth \\
\hline Beta-226694 & Populus sp./Salix sp. Cf. Populus sp. & -27.4 & 2320 & 40 & $2463-2161$ & Hearth \\
\hline OS-81751 & Picea & -24.05 & 2350 & 25 & $2459-2331$ & Hearth \\
\hline OS-81648 & Picea & -25.86 & 2350 & 35 & $2652-2317$ & Hearth \\
\hline OS-78458 & Picea & -25.40 & 2450 & 40 & $2705-2358$ & Hearth \\
\hline OS-78459 & Picea & -24.45 & 2630 & 25 & $2780-2735$ & Hearth \\
\hline Beta-226695 & Populus sp./Salix sp. Cf. Populus sp. & -25.5 & 2930 & 40 & $3215-2958$ & Hearth \\
\hline OS-78586 & Picea & -22.87 & 3450 & 30 & $3829-3637$ & Hearth \\
\hline OS-78551 & Picea & -24.39 & 3760 & 35 & $4238-3990$ & Hearth \\
\hline OS-78547 & Salicaceae-Populus/Salix & -24.67 & 175 & 25 & $290--4$ & House \\
\hline Beta-226150 & Pinaceae Cf. Picea/Larix sp. & -24.2 & 190 & 40 & $306--4$ & House \\
\hline OS-78545 & Picea & -25.27 & 260 & 30 & $431--3$ & House \\
\hline Beta-223219 & Populus sp. & -25.6 & 280 & 40 & $469--1$ & House \\
\hline Beta-226153 & Picea sp./Larix sp. & -25.2 & 320 & 40 & $483-301$ & House \\
\hline OS-81616 & Picea & -25.35 & 355 & 30 & $498-316$ & House \\
\hline Beta-226148 & Salix sp. & -27.5 & 380 & 40 & $509-316$ & House \\
\hline Beta-226692 & Populus sp./Salix sp. Cf. Populus sp. & -25.6 & 390 & 40 & $514-316$ & House \\
\hline Beta-226149 & Picea sp./Larix sp. Cf. Picea sp. & -23.7 & 400 & 40 & $518-317$ & House \\
\hline Beta-226687 & Pinaceae & -23.4 & 470 & 40 & $621-342$ & House \\
\hline Beta-226151 & Picea sp./Larix sp. & -24.9 & 570 & 40 & $652-521$ & House \\
\hline OS-81582 & Salicaceae - twig & -27.33 & 570 & 25 & $644-530$ & House \\
\hline OS-81678 & Salicaceae, cf. Salix - twig & -26.29 & 650 & 30 & $670-556$ & House \\
\hline OS-78583 & Picea & -29.20 & 675 & 25 & $676-561$ & House \\
\hline OS-81743 & Salicaceae, cf. Salix & -25.85 & 720 & 25 & $695-570$ & House \\
\hline Beta-226152 & Picea sp./Larix sp. & -25.1 & 1050 & 40 & $1059-915$ & House \\
\hline Beta-226154 & Picea sp./Larix sp. & -26.9 & 1200 & 40 & $1261-1004$ & House \\
\hline OS-81430 & Picea & -25.94 & 1230 & 25 & $1260-1070$ & House \\
\hline OS-78457 & Picea & -24.62 & 1300 & 35 & $1294-1174$ & House \\
\hline OS-81403 & Unidentifiable & -24.52 & 1300 & 50 & $1304-1085$ & House \\
\hline OS-78455 & Salicaceae-Salix/Populus & -26.87 & 1410 & 25 & $1350-1289$ & House \\
\hline OS-81750 & Picea & -23.49 & 1450 & 30 & $1389-1299$ & House \\
\hline Beta-226155 & Pinaceae Cf. Picea/Larix sp. & -26.5 & 1510 & 40 & $1518-1313$ & House \\
\hline OS-78460 & Salicaceae & -26.30 & 1510 & 30 & $1515-1327$ & House \\
\hline
\end{tabular}

Page $\mathbf{3 7}$ of $\mathbf{4 0}$ 


\begin{tabular}{|c|c|c|c|c|c|c|}
\hline OS-81756 & Picea & -24.67 & 1590 & 25 & $1534-1411$ & House \\
\hline OS-81649 & Picea & -23.73 & 1600 & 35 & $1560-1405$ & House \\
\hline Beta-226693 & Picea sp./Larix sp. & -25.4 & 1780 & 40 & $1820-1572$ & House \\
\hline OS-81429 & Salicaceae, cf. Salix & -27.08 & 1780 & 25 & $1814-1616$ & House \\
\hline OS-78461 & Picea & -24.64 & 1920 & 30 & $1948-1745$ & House \\
\hline OS-81753 & Salicaceae & -23.04 & 2430 & 25 & $2696-2353$ & House \\
\hline OS-81746 & Picea & -23.94 & 110 & 30 & $270-12$ & Indeterminate \\
\hline OS-78584 & Salicaceae & -25.69 & 330 & 25 & 469-308 & Indeterminate \\
\hline OS-81645 & Salicaceae,cf.Populus & -26.44 & 465 & 40 & $617-338$ & Indeterminate \\
\hline OS-81441 & Salicaceae, cf. Salix - twig & -27.42 & 510 & 30 & $622-505$ & Indeterminate \\
\hline OS-78585 & Salicaceae & -26.51 & 590 & 35 & $654-535$ & Indeterminate \\
\hline OS-78548 & Betula & -25.64 & 670 & 25 & $674-561$ & Indeterminate \\
\hline OS-78620 & Salicaceae & -25.14 & 690 & 30 & $685-562$ & Indeterminate \\
\hline OS-81574 & R. tarandus, meta tarsl/carp & -19.36 & 805 & 25 & $765-678$ & Indeterminate \\
\hline OS-81277 & Picea & -24.71 & 830 & 35 & $892-678$ & Indeterminate \\
\hline OS-81434 & Picea & -24.57 & 830 & 30 & $791-686$ & Indeterminate \\
\hline OS-78619 & Salicaceae & -24.32 & 835 & 25 & $788-691$ & Indeterminate \\
\hline OS-81744 & Picea & -23.72 & 865 & 25 & $902-699$ & Indeterminate \\
\hline OS-81577 & R. tarandus, mandible & -18.71 & 875 & 20 & $900-731$ & Indeterminate \\
\hline OS-78549 & Picea & -25.00 & 995 & 25 & $962-799$ & Indeterminate \\
\hline OS-81968 & Picea & -27.09 & 1210 & 80 & $1285-972$ & Indeterminate \\
\hline OS-81638 & Picea & -25.38 & 1290 & 35 & $1295-1145$ & Indeterminate \\
\hline OS-78456 & Salicaceae & -25.67 & 1330 & 35 & $1305-1178$ & Indeterminate \\
\hline OS-81436 & Picea & -25.60 & 1410 & 30 & $1360-1285$ & Indeterminate \\
\hline OS-81650 & Picea & -25.48 & 1490 & 35 & $1509-1305$ & Indeterminate \\
\hline OS-78550 & Salicaceae & -25.17 & 1510 & 30 & $1515-1327$ & Indeterminate \\
\hline OS-81658 & Salicaceae, cf. Salix - twig & -25.83 & 1560 & 45 & $1538-1354$ & Indeterminate \\
\hline OS-81439 & Picea & -25.09 & 1590 & 30 & $1540-1407$ & Indeterminate \\
\hline OS-81280 & Picea & -24.51 & 1600 & 25 & $1538-1414$ & Indeterminate \\
\hline OS-81284 & Salicaceae, cf. Salix & -26.11 & 1600 & 25 & $1538-1414$ & Indeterminate \\
\hline OS-81609 & Picea & -24.74 & 1610 & 30 & $1558-1412$ & Indeterminate \\
\hline OS-81425 & Picea & -22.65 & 1620 & 25 & 1561-1416 & Indeterminate \\
\hline OS-81613 & Picea & -23.92 & 1620 & 30 & $1593-1412$ & Indeterminate \\
\hline OS-78588 & Salicaceae & -26.03 & 1630 & 25 & $1601-1416$ & Indeterminate \\
\hline OS-81605 & Picea & -23.85 & 1670 & 25 & $1689-1523$ & Indeterminate \\
\hline
\end{tabular}

Page 38 of $\mathbf{4 0}$ 


\begin{tabular}{|c|c|c|c|c|c|c|}
\hline OS-81620 & Picea & -24.44 & 1700 & 25 & $1694-1540$ & Indeterminate \\
\hline OS-81684 & Salicaceae, cf. Salix & -27.37 & 1770 & 25 & $1811-1607$ & Indeterminate \\
\hline OS-81433 & Conifer & -26.18 & 1780 & 25 & $1814-1616$ & Indeterminate \\
\hline OS-81278 & Picea & -25.01 & 1800 & 25 & $1820-1628$ & Indeterminate \\
\hline OS-81608 & Picea & -26.66 & 1820 & 30 & $1860-1633$ & Indeterminate \\
\hline OS-81426 & Picea & -25.18 & 1870 & 25 & $1875-1729$ & Indeterminate \\
\hline OS-81437 & Picea & -25.15 & 1880 & 30 & $1885-1727$ & Indeterminate \\
\hline OS-81583 & Salicaceae, cf. Populus & -26.66 & 2000 & 25 & $1998-1890$ & Indeterminate \\
\hline OS-81636 & Salicaceae, cf. Salix & -24.73 & 2000 & 35 & 2041-1874 & Indeterminate \\
\hline OS-81749 & Salicaceae, cf. Populus & -25.30 & 2500 & 30 & $2732-2467$ & $\begin{array}{c}\text { Probable Activity } \\
\text { Area }\end{array}$ \\
\hline OS-81652 & Betula & -23.94 & 375 & 40 & $507-316$ & Surface Scatter \\
\hline OS-81745 & Betula & -24.84 & 435 & 25 & $526-465$ & Surface Scatter \\
\hline OS-81680 & Picea & -23.57 & 495 & 25 & $543-505$ & Surface Scatter \\
\hline OS-81641 & Salicaceae - twig, friable & -23.12 & 760 & 35 & $736-662$ & Surface Scatter \\
\hline OS-78587 & Salicaceae & -25.61 & 1590 & 25 & $1534-1411$ & Surface Scatter \\
\hline OS-81676 & Salicaceae, cf. Salix & -27.82 & 1610 & 25 & $1548-1415$ & Surface Scatter \\
\hline OS-81754 & Picea & -21.77 & 1620 & 25 & $1561-1416$ & Surface Scatter \\
\hline OS-81646 & Picea & -24.75 & 1840 & 35 & $1870-1704$ & Surface Scatter \\
\hline OS-81755 & Picea & -24.15 & 1990 & 25 & 1993-1886 & Surface Scatter \\
\hline OS-78590 & Salicaceae-Salix/Populus & -24.36 & 2100 & 25 & 2140-1999 & Surface Scatter \\
\hline OS-81655 & Picea & -25.81 & 2170 & 35 & $2314-2060$ & Surface Scatter \\
\hline OS-81607 & Picea & -24.11 & 2210 & 30 & 2325-2149 & Surface Scatter \\
\hline OS-81643 & Unidentifiable & -25.24 & 2280 & 35 & $2352-2158$ & Surface Scatter \\
\hline OS-78589 & Salicaceae & -26.46 & 2380 & 25 & $2485-2341$ & Surface Scatter \\
\hline OS-81651 & Salicaceae, cf. Salix & -26.81 & 3090 & 35 & $3381-3218$ & Surface Scatter \\
\hline
\end{tabular}


Table 5. Areas of the beach ridge complex surveyed by the current project

\begin{tabular}{cccc}
\multicolumn{4}{c}{ Area (hectares) } \\
\hline $\begin{array}{c}\text { Beach } \\
\text { Segment }\end{array}$ & Total & Surveyed & $\begin{array}{c}\text { Percent } \\
\text { Coverage }\end{array}$ \\
\hline None* & 498 & 44 & $9 \%$ \\
I & 256 & 91 & $36 \%$ \\
II & 581 & 485 & $83 \%$ \\
III & 238 & 154 & $65 \%$ \\
IV & 735 & 293 & $40 \%$ \\
V & 385 & 121 & $31 \%$ \\
VI & 640 & 351 & $55 \%$ \\
Total* & 2835 & 1495 & $53 \%$ \\
\hline
\end{tabular}

* Areas not part of the beach ridge complex itself are not included in total

Table 6. Features identified by current project

Beach Segment

\begin{tabular}{lccccccr}
\hline Feature Type & I & II & III & IV & V & VI & Total \\
\hline Hearth & 1 & 15 & 13 & 33 & 31 & 8 & 101 \\
Cache Pit & 95 & 176 & 7 & 3 & 1 & 1 & 283 \\
House & 35 & 92 & 9 & 12 & 0 & 0 & 148 \\
Surface Scatter & 12 & 18 & 19 & 34 & 15 & 5 & 103 \\
Burial & 4 & 5 & 2 & 0 & 0 & 0 & 11 \\
Unspecified Surface & 168 & 401 & 110 & 16 & 19 & 17 & 731 \\
Depressions & $\mathbf{3 1 5}$ & $\mathbf{7 0 7}$ & $\mathbf{1 6 0}$ & $\mathbf{9 8}$ & $\mathbf{6 6}$ & $\mathbf{3 1}$ & $\mathbf{1 3 7 7}$ \\
Total & 65 & 156 & 16 & $\mathbf{2}$ & $\mathbf{1}$ & 0 & 240 \\
Vegetation Anomaly & & & & & & & \\
\hline
\end{tabular}

